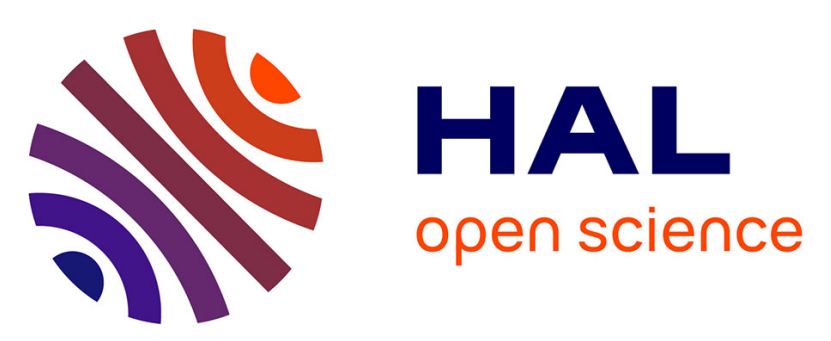

\title{
Effect of the annealing process on the microstructure of La2Zr2O7 thin layers epitaxially grown on LaAlO3 by metalorganic decomposition
}

\author{
Carmen Jiménez, Tristan Caroff, L. Rapenne, Stéphanie Morlens, Elena \\ Santos, Philippe Odier, François Weiss
}

\section{To cite this version:}

Carmen Jiménez, Tristan Caroff, L. Rapenne, Stéphanie Morlens, Elena Santos, et al.. Effect of the annealing process on the microstructure of $\mathrm{La} 2 \mathrm{Zr} 2 \mathrm{O} 7$ thin layers epitaxially grown on LaAlO3 by metalorganic decomposition. Journal of Crystal Growth, 2009, 311, pp.3204. 10.1016/j.jcrysgro.2009.03.021 . hal-00395314

\section{HAL Id: hal-00395314 \\ https://hal.science/hal-00395314}

Submitted on 15 Jun 2009

HAL is a multi-disciplinary open access archive for the deposit and dissemination of scientific research documents, whether they are published or not. The documents may come from teaching and research institutions in France or abroad, or from public or private research centers.
L'archive ouverte pluridisciplinaire HAL, est destinée au dépôt et à la diffusion de documents scientifiques de niveau recherche, publiés ou non, émanant des établissements d'enseignement et de recherche français ou étrangers, des laboratoires publics ou privés. 
Effect of the annealing process on the microstructure of $\mathrm{La}_{2} \mathrm{Zr}_{2} \mathrm{O}_{7}$ thin layers epitaxially grown on $\mathrm{LaAlO}_{3}$ by metalorganic decomposition

\author{
C. Jiménez ${ }^{1}$, T .Caroff ${ }^{1,2}$, L. Rapenne ${ }^{1}$, S. Morlens ${ }^{2}$, E. Santos ${ }^{1}$, P. Odier $^{2}$, F.Weiss $^{1}$ \\ 1 - LMGP - UMR 5628 CNRS - Grenoble INP -Minatec. 3, parvis Louis Néel, BP 257, \\ 38016 Grenoble France
}

2 - Institut Néel/CRETA - CNRS UPS2070- 25, avenue des Martyrs - BP 166 - 38042 Grenoble - France

\begin{abstract}
$\mathrm{La}_{2} \mathrm{Zr}_{2} \mathrm{O}_{7}$ (LZO) films have been grown by Metalorganic Decomposition (MOD) to be used as buffer layers for coated conductors. A characteristic feature of LZO thin films deposited by MOD is the formation of nanovoids in an almost single crystal structure of LZO pyrochlore phase. Annealing parameters (heating ramp, temperature, pressure...) were varied to establish their influence on the microstructure of the LZO layers. XRD and TEM were used for sample characterisation. The epitaxial pyrochlore phase was obtained for annealing temperatures higher that $850^{\circ} \mathrm{C}$ whatever the other annealing conditions. However, the film microstructure, in particular, nanovoids shape and size, is strongly dependent on heating ramp and pressure during annealing. When using low heating ramp, percolation of voids creates diffusion channels for oxygen which are detrimental for the substrate protection during coated conductor fabrication. From this point of view high heating rates are more adapted to the growth of LZO layers.
\end{abstract}

Keywords:

68.37.Lp Transmission electron microscopy (TEM);

68.55.A- Nucleation and growth;

81.15.-z Methods of deposition of films and coatings; film growth and epitaxy;

84.71.Mn Superconducting wires, fibers, and tapes 


\section{Introduction}

Coated conductors developed from Rolling Assisted Biaxially Textured substrates (RABiTs) [1,2] are considered a low cost architecture because nickel-based textured substrates are used as template to biaxially grow the superconducting $\mathrm{YBa}_{2} \mathrm{Cu}_{3} \mathrm{O}_{7}$ (YBCO) layer [3]. A simple low cost architecture obtained by all-chemical routes consisting in $\mathrm{YBCO}_{\mathrm{MOCVD}} / \mathrm{La}_{2} \mathrm{Zr}_{2} \mathrm{O}_{7 \mathrm{MOD}} / \mathrm{NiW}$ RABiTS $(\mathrm{MOCVD}=$ Metalorganic Chemical Vapor Deposition, $\mathrm{MOD}=$ Metalorganic Decomposition) has been already validated in a previous work [4] $\mathrm{La}_{2} \mathrm{Zr}_{2} \mathrm{O}_{7}$ (LZO) buffer layers grown by MOD have been also tested in other architecture where YBCO was deposited by other methods like PLD [5] or MOD [6]

The role of the buffer layer is double: to ensure the texture transmission from the texture substrates to the superconducting layer with a good lattice matching, and to protect the metallic substrate against oxidation. Pyrochlore LZO behaves as a buffer layer in this architecture because its lattice parameters match those of $\mathrm{YBCO}\left(\left|\left(\varepsilon_{\mathrm{YBCO}}-\varepsilon_{\mathrm{LZO}}\right) / \varepsilon_{\mathrm{LZO}}\right|=\right.$ $1.05 \%$ ), and also because it provides a good barrier against $\mathrm{O}_{2}$ diffusion [7]. LZO pyrochlore structure (Space Group: Fd-3m, 73-0444, lattice parameter $a=10.808 \AA$ ) is derived from the LZO fluorite structure (Space Group: Fm-3m, 75-0346, lattice parameter a= $5.407 \AA$ ) with one-eighth of the anions absent and two distinct cation sites. These two structures can be distinguished by the presence of the (111) and (331) reflections in the pyrochlore phase, corresponding to spacing values of $6.24 \AA$ and $2.48 \AA$ with an intensity of $3 \%$ and $5 \%$ respectively, which do not exist in the fluorite structure. Ni5\%atW RABiTs present a cube texture $\{100\}<001>$ (Space Group: Fm3m, lattice parameter $a=3.545 \AA$ [8]); so it is well adapted to ensure the epitaxial growth of the LZO layer, whose unit cell is rotated of $45^{\circ}$ in order to match the $\mathrm{Ni}$ unit cell. The epitaxial relationships are $[100]_{\mathrm{Ni}} / /[110]_{\mathrm{LzO}}$; $[010]_{\mathrm{Ni}} / /[\overline{1} 10]_{\mathrm{LZO}}$ and $[001]_{\mathrm{Ni}} / /[001]_{\mathrm{LZO}}$.

A characteristic feature of LZO thin films deposited by Metalorganic Decomposition (MOD) is the formation of nanovoids in an almost single crystal structure of LZO pyrochlore phase [9]. MOD process is a two-steps process: pyrolysis and crystallization. The pyrolisis is probably at the origin of the apparition of these cavities. The decomposition of the metalorganic precursors occurs during the thermal treatment, which is performed under an $\mathrm{Ar}+\mathrm{H}_{2}$ atmosphere to avoid the oxidation of the substrate. Our standard thermal profile consists in a heating ramp at $500^{\circ} \mathrm{C} / \mathrm{h}$ up to $980^{\circ} \mathrm{C}$ followed by a dwell at $980^{\circ} \mathrm{C}$ for $30 \mathrm{~min}$. The cooling rate corresponds to the thermal inertia of the furnace. Pyrolysis takes place during 
the first part of the annealing at low temperature $\left(\mathrm{RT}-500^{\circ} \mathrm{C}\right)$, and crystallisation occurs at higher temperatures. A detailed study by TEM on samples annealed in standard conditions is presented in [9]. Generally, voids or nanovoids were observed either spherical or hexagonal, their faces corresponding to the (111) plane front. The most frequent void size is around 20 $\mathrm{nm}$ diameter, but it seems that bigger voids are also present. We did not find coalescence of nanovoids in samples observed in our previous work. The voids in LZO can be at the origin of the oxygen diffusion through the layer observed by Paranthaman et al [10]. The effective thickness is smaller, and films have to be thicker in order to reduce oxygen diffusion. This point is very important in the optimisation of the coated conductor architecture.

This work focuses on the influence of the parameters of the thermal treatment on the microstructure of LZO thin layers grown on $\mathrm{LaAlO}_{3}$ (LAO) single crystal substrates from propionates by MOD. Results on XRD are compared with the electron diffraction obtained by TEM to determine the fluorite or pyrochlore formation. The microstructure of these films is related to the synthesis process.

\section{Experimental}

Lanthanum zirconate was produced by MOD according to a procedure previously described [11]. Lanthanum (III) 2, 4-pentadionate and zirconium (IV) 2, 4-pentadionate were dissolved in propionic acid $\left(\mathrm{CH}_{3}-\mathrm{CH}_{2}-\mathrm{COOH}\right)$ to form lanthanum and zirconium propionates. Propionic acid was added to get a total cations concentration of $0.6 \mathrm{~mol} / \mathrm{l}$. LZO layers were grown on $\mathrm{LaAlO}_{3}(\mathrm{LAO})$ single crystals. LAO presents a rhombohedral structure (Space Group: R3m; a=5.364 $\AA$, c=13.11 ), but we have preferred to simplify the interpretation by using the pseudocubic (pc) perovskite structure of LAO (Space Group: Pm-3m; 073-3584; $\left.\mathrm{a}_{\mathrm{pc}}=3.7913 \AA\right)$. LAO single crystals provided by Crystec $\mathrm{GmbH}(001)_{\mathrm{pc}}$ oriented were used as substrates and all diffraction patterns presented in this work are indexed with pseudocubic indices. The epitaxial relationships of LAO (as for Ni textured substrate) with LZO are described by $[100]_{\mathrm{LAO}} / /[110]_{\mathrm{LZO}}[010]_{\mathrm{LAO}} / /[\overline{1} 10]_{\mathrm{LZO}}$ and $[001]_{\mathrm{LAO}} / /[001]_{\mathrm{LZO}}$.

Before deposition, the substrates were ultrasonically cleaned in isopropanol during 10 min. LZO films were deposited by dip coating at room temperature in a glove box. The substrates were immersed for $30 \mathrm{~s}$ in the solution and withdrawn at the rate of $6 \mathrm{~cm} / \mathrm{min}$. The 
samples were then dried at $80^{\circ} \mathrm{C}$ using infrared lamps for $60 \mathrm{~s}$ inside the glove box. The films were annealed under $\mathrm{Ar}+5 \% \mathrm{H}_{2}$ gas flow $(30 \mathrm{slm})$ at 1 bar. The heating rate and the annealing temperature were modified in this study. The cooling rate in all the cases corresponds to the furnace thermal inertia. Our standard thermal profile consists in a heating ramp at $500^{\circ} \mathrm{C} / \mathrm{h}$ up to $980^{\circ} \mathrm{C}$ followed by a dwell at $980^{\circ} \mathrm{C}$ for $30 \mathrm{~min}$. A standard annealing was also performed under vacuum $\left(10^{-2} \mathrm{mbar}\right)$.

Film texture and epitaxial relationships among the different layers were determined by XRay Diffraction (XRD) with the Shultz geometry using a D5000 Siemens four-circle diffractometer with monochromatic $\mathrm{Cu} \mathrm{K} \alpha$ radiation $(\lambda=0.15418 \mathrm{~nm})$.

Transmission electron microscopy and electron diffraction were carried out on a JEOL 2011 operating at $200 \mathrm{kV}$ with a $0.19 \mathrm{~nm}$ point to point resolution. Cross-sections of LZO/LAO samples were obtained by the tripod method. Samples were polished on both sides to less than $15 \mu \mathrm{m}$ thick by using diamond impregnated films with a grain size varying from $15 \mu \mathrm{m}$ sequentially down to $0.5 \mu \mathrm{m}$. Low angle ion beam milling was used for final perforation of the samples and to minimise contamination. Samples prepared for TEM observation and described in the results section have been resumed in Table 1.

\section{Results}

The solution and the dip coating conditions were the same for all the samples. At the withdrawal speed used in this work the grown layers present a thickness of $\sim 80 \mathrm{~nm}$ after annealing. The annealing temperature and the heating rate effect on the crystal quality and on the microstructure of LZO were studied by XRD and by TEM. As presented in [9], substrates have an important role on texture transmission but not on microstructure, mainly established by growth phenomenon. In this frame, results obtained on LAO can be considered also as applicable to metallic substrate. The name and general description of each sample studied are presented in Table I.

The schematic representations of the annealing are summarized in Figure 1a for the annealing temperature variation and in Figure $1 \mathrm{~b}$ for the heating ramp variation. Sample 
LZO4 corresponds to the standard annealing. For further details, a complete study of sample annealed in standard conditions has been presented in [9]. An annealing under vacuum was also performed to establish the influence of pressure during the process. XRD results obtained from all the samples are presented in the $\theta-2 \theta$ diagram of figure $2 \mathrm{a}$. The (400) reflection peaks appear at angles higher than that expected for LZO (in compression as $\left(\varepsilon_{\mathrm{LAO}}-\varepsilon_{\mathrm{LZO}}\right) / \varepsilon_{\mathrm{LZO}}$ $=-0.8 \%)$. This shift is less important for LZO5 sample. Figure $2 b$ shows the XRD diagram of the LZO7 sample in logarithmic representation. The labels indicate the origin of the peaks.

\section{i) Annealing temperature effect}

The annealing profiles were similar for this experimental series. It consisted of a heating ramp of $500^{\circ} \mathrm{C} / \mathrm{h}$ from room temperature up to the annealing temperature, and then 5 minutes kept at this temperature, except for LZO4 prepared with the standard annealing with a dwell of $30 \mathrm{~min}$. Short dwell times were used to determine the crystalline state of the sample before reaching the standard annealing temperature. Temperatures ranging from $500^{\circ} \mathrm{C}$ to $960^{\circ} \mathrm{C}$ were used in this study corresponding to samples LZO1, LZO2, LZO3 and LZO4.

Films are amorphous up to $\sim 800^{\circ} \mathrm{C}$, so samples LZO1 and LZO2 present no diffracted signal by XRD. Figure 2a shows the samples annealed at $850^{\circ} \mathrm{C}(\mathrm{LZO} 3)$ and $960^{\circ} \mathrm{C}(\mathrm{LZO} 4)$; the other annealing conditions are resumed in table 1 . For well-crystallised films, $\varphi$-scans and rocking curves could confirm the biaxial texture of the samples. As it can be seen in figure 2a, except for the LZO3 sample, the LZO(400) reflection intensity varies from 5500 to 12000 cps, and the $\mathrm{LZO}(222)$ reflection is not detected.

LZO1 sample corresponding to the lowest annealing temperature $\left(500^{\circ} \mathrm{C}\right)$ was observed by TEM (Figure 3). The sample was stable under the electron beam, which indicates that the material did not contain organic compounds which could be burnt under the electron beam. The layer was amorphous, but a variation of contrast can be already observed at this temperature. We presumed these zones to be voids [9], but due to the amorphous state, it was not possible to strictly identify this inclusion as voids. Their mean size was $5 \mathrm{~nm}$.

LZO2 sample observed by TEM was still amorphous, as shown in the electron diffraction pattern included in Figure 4 and in agreement with the XRD results. The variation of contrast was also visible in this sample, but it seems that their size was slightly bigger (around $10 \mathrm{~nm}$ ). 
LZO3 sample was analysed by XRD and a small contribution at $2 \theta \sim 33.2^{\circ}$ corresponding to LZO crystallization was detected. The intensity was too small to perform a detailed analysis on phase identification. When observed by TEM in cross section, an electron diffraction pattern corresponding to fluorite phase in the [110] axis zone could be indexed (Figure 5). The sample was well crystallised through all its thickness, and the substrate texture was well-transmitted up to the surface. The pyrochlore phase was not easily detected in this layer, and only when using small diaphragm and working at the substrate-LZO interface it could be possible to detect very slight (111) and (331) reflections attributed to the pyrochlore structure.

LZO4 sample corresponds to the standard annealing, already discussed in [9]. In these conditions, the LZO layer was well crystallised and the pyrochlore structure could be easily identified. Voids detected in this sample were around $20 \mathrm{~nm}$. A representative picture of this sample is given in Fig 6.

Annealing temperature is the main parameter that controls the crystallisation advance. Films are amorphous below $800^{\circ} \mathrm{C}$ and crystallize, at first, in fluorite structure. The crystalline order increases with temperature and films transform into pyrochlore at higher temperatures, hardly detected at $850^{\circ} \mathrm{C}$. Besides, voids seems to be already included in the amorphous structure and interestingly do not influence the crystalline final state.

\section{ii) Heating ramp effect}

LZO4, LZO5, LZO6 samples were prepared at different heating rate up to the same annealing temperature of $960^{\circ} \mathrm{C}$. The annealing dwell was $30 \mathrm{~min}$ in all the experiments.

The lowest ramp was $100^{\circ} \mathrm{C} / \mathrm{h}$ corresponding to the LZO5 sample. This layer presented a very strong (400) reflection in XRD analysis (Figure 2a), almost the double than that of the LZO6 sample, corresponding to the highest heating ramp. From this result, it could be inferred that low heating ramp enhances crystallization. On the other hand, the shift in the position of the (400) reflection peak is less important for LZO5 sample, so stress has been also relaxed. The cross section observation by TEM of the LZO5 sample is presented in the Figure 7 together with the electron diffraction pattern. The crystal structure was pyrochlore in the [110] axis zone and the (111) and (331) reflections were strongly visible when compared to previous results. Nevertheless, the microstructure was also really different. Voids were bigger than in standard annealing and they percolated almost in the entire thickness of the 
sample. This morphology can be at the origin of the stress relaxation detected by XRD. Besides, the sample is less compact and the generation of channels for oxygen migration can be a detrimental aspect for the diffusion barrier behaviour. Moreover, the surface is also influenced by this morphology and it presents a larger roughness than sample LZO4.

The LZO6 sample corresponds to the highest ramp $\left(1400^{\circ} \mathrm{C} / \mathrm{h}\right)$. TEM observation in cross section (Figure 8) shows that the layer is well-crystallised in pyrochlore structure as identified in the electron diffraction pattern. Nanovoids were small, with very sharp edges corresponding to [111] directions, and they were not connected. From this point of view; the layer was more compact. Its surface was also smoother than in precedent sample. When compared to standard annealing, there are not strong differences, but voids seem more regular and there are less deviation from the mean size.

The main effect of the heating rate is on microstructure; otherwise the LZO layers present a well-textured pyrochlore structure in all cases. Reactions proceeding during pyrolysis need the evacuation of pyrolysis products. The diffusion of these products generates voids and channels in the viscous matrix, which is plastic in a specific temperature range. For higher temperatures, the matrix starts solidification and recovering of the films is not possible anymore. The deformation of the matrix can be thus identified after nucleation. This phenomenon is exacerbated at low heating rates because it means longer time for pyrolysis and deformation.

\section{iii) Vacuum annealing}

We also performed a standard thermal profile under vacuum to set the influence of pressure on the LZO growth. This experiment corresponds to the LZO7 sample. XRD on this sample presented the highest intensity for the (400) LZO reflection (Figure 2a and 2b). When observed by TEM in cross section, the sample showed the pyrochlore structure with very intense (111) and (331) reflections and the characteristic nanovoids were also visible through the layer thickness. However voids were spherical in this case and their sizes larger than for the standard annealing. This result confirms the hypothesis that voids are formed during the pyrolysis step and caused by gas generation. Processes at low pressure creates round cavities 
in a temperature range where the film is rather plastic, they cannot be transformed in regular cavities during the nucleation step.

\section{Discussion}

MOD process is a two step process consisting of pyrolisis at low temperature and of nucleation and growth of the crystalline phase at higher temperature. For coated conductors applications, the nucleation should only present a hetereogeneous contribution to ensure the transmission of texture from the substrate through the films towards the surface. The characterization technique generally used for crystalline quality determination is XRD, which probes the whole thickness and it can be implemented as on-line control in production. Special procedures have been recently developed for estimating the epitaxial fraction in the layer volume by XRD [12]. This technique can also give information about in-plane and outof-plane texture of the layer. Alternative techniques to determine the crystalline quality of the surface are EBSD and RHEED, which need vacuum systems and can be only used on small samples [13]. Otherwise, crystalline quality can be probed by TEM [14]. However, this technique needs a hard and long preparation step and it can be only used for exploratory works. Nevertheless, for experimental studies and in order to understand the effect of the growth parameters on the sample quality, TEM seems to be well-adapted to supply complementary information to XRD analysis about crystalline quality and to reveal the microstructure.

We have determined the microstructure of LZO samples annealed with different thermal profiles. A temperature above $800^{\circ} \mathrm{C}$ is necessary to crystallize the $\mathrm{LZO}$ layer. The crystalline quality evolves from fluorite to pyrochlore structure at higher temperatures, indicating an increasing crystalline order: in pyrochlore structure, cations present an order which does not exist in the case of fluorite. It is known that $\mathrm{Ln}_{2} \mathrm{Zr}_{2} \mathrm{O}_{7}(\mathrm{Ln}=$ Lanthanide $\mathrm{La}$ to $\mathrm{Gd}$ ) pyrochlore phases are stable at RT but at high temperature $\left(>1500^{\circ} \mathrm{C}\right)$, an order-disorder transition from pyrochlore to fluorite occurs. Theoretically La-pyrochlore does not present such transition, and then LZO cannot exist in fluorite phase [15]. In our case, fluorite structure appears as a metastable phase which transforms into pyrochlore (the stable phase) between $850^{\circ} \mathrm{C}$ and $960^{\circ} \mathrm{C}$. This transformation is relatively fast, because using the standard heating ramp of $500^{\circ} \mathrm{C} / \mathrm{h}$, the transformation takes place in less than $15 \min (\sim 0.1 \mathrm{~nm} / \mathrm{s})$. XRD diffraction 
allows to follow this increase of crystalline quality by recording the $\mathrm{LZO}(400)$ reflection intensity.

The origin of voids is related to gas accumulation as inferred from the sample annealed under vacuum. If voids are already present at $500^{\circ} \mathrm{C}$, it means that gas accumulation takes place during the low temperature annealing step concerning pyrolysis of the organic precursor used in this MOD process. TGA performed separately for each precursor shows that main mass losses take place between $300^{\circ} \mathrm{C}$ and $400^{\circ} \mathrm{C}$ [11]. The shrinking in thickness also occurs in this temperature range. We can then suppose that pyrolysis is already finished at $500^{\circ} \mathrm{C}$ and that the matrix is stable, as corroborated by TEM analysis. On the other hand, EFTEM analysis on standard samples previously reported in [9] confirms that voids contain no carbon inside or the carbon level is the same in nanovoids than in the rest of the sample. So pyrolysis products have been already evacuated in the standard conditions before crystallization. It would be important to establish the process involved in accumulation and in evacuation of products during pyrolysis. This understanding, currently under study, would allow to improve the LZO microstructure by a better control of voids formation.

The choice of lanthanum zirconate is justified by the good lattice matching with YBCO and by its good properties as diffusion barrier to protect substrate against oxidation. [16]. From results shown above, it is seen that oxygen diffusion will be strongly dependent on the microstructure of the layer, so on the thermal profile of crystallisation. Using low heating rates is not compatible with coated conductor fabrication, because the effective thickness is reduced to few nanometers due to voids percolation. These diffusion channels for oxygen are detrimental for the substrate protection during YBCO deposition. The formation of channels takes place during pyrolysis, in the amorphous matrix, which sinters by viscous flow [17]. For fast heating, this step is squeezed and pores cannot coalesce in channels. Pores are then distributed randomly within the bulk of the film. Then fast heating seems more appropriate to avoid percolated porosity, it has also no detrimental effect on the crystallization as shown in this paper. On the other hand, high heating rates allow to decrease the crystallization driving forces, which would delay the densification and crystallization processes to higher temperatures [18]. From this point of view, high heating rates are more adapted to the formation of denser and better crystallized films. 
When using different heating ramp up to the same annealing temperature $\left(960^{\circ} \mathrm{C}\right)$, the crystalline state is characterised by the formation of the pyrochlore phase. Nevertheless, microstructure is really different for each annealing profile and it can present detrimental aspects for coated conductor applications. It seems evident that crystalline quality cannot be considered as the only specifications for sample quality, and that a deeper understanding on the pyrolysis process is the key to control the microstructure. Even if standard annealing leads to excellent LZO which can be used in single buffer layer architectures [4], the optimisation of the MOD process need the optimisation of the pyrolysis step and the crystallization step separately

Heterogeneous nucleation is possible whatever the annealing conditions in the temperature range used for this study are. The nucleation front starts at the substrate-layer interface and moves towards the surface. Voids do not interfere with the crystallization process. It seems that the carbon content linked with the pyrolysis can have an important role on the crystallization step. In our case, there is no carbon in the standard annealed sample. Further study should be performed with different pyrolysis conditions to understand the influence of this step on the nucleation and crystallization step, as well as on the microstructure.

\section{Conclusions}

$\mathrm{La}_{2} \mathrm{Zr}_{2} \mathrm{O}_{7}$ (LZO) films grown by Metalorganic Decomposition (MOD) present a characteristic feature: the formation of nanovoids in an almost single crystal structure of LZO pyrochlore phase. Annealing parameters (heating ramp, temperature, atmosphere...) were varied and XRD and TEM were used to establish their influence on the microstructure of the LZO layers.

Epitaxial pyrochlore phase was obtained for annealing temperatures higher that $850^{\circ} \mathrm{C}$ whatever the other annealing conditions. Films are amorphous below $800^{\circ} \mathrm{C}$. At $850^{\circ} \mathrm{C}$, layers crystallise in LZO fluorite structure, which transforms into pyrochlore structure at higher temperatures. Voids present in the crystallised samples are already visible in the amorphous matrix at $500^{\circ} \mathrm{C}$. 
Besides, microstructure is strongly dependent on the heating ramp and pressure during annealing. In particular, nanovoids shape and size are influenced by the heating ramp. Using low heating ramp, percolation of voids creates diffusion channels for oxygen which are detrimental for the substrate protection during YBCO deposition. When using high heating ramp, voids are regular and homogeneously distributed without connexion. When annealing under vacuum, voids are spherical indicating their origin by gas accumulation.

\section{Acknowledgement}

This work has been financially supported by the French Research National Agency (ANR) through the MADISUP Project and by Région Rhône-Alpes SESUC project.

\begin{tabular}{|c|c|c|c|}
\hline Name & Heating ramp ("C/h) & Temperature ( $\mathrm{C}$ ) & Annealing time (min) \\
\hline IZOI & 500 & 500 & 5 \\
\hline 1202 & 500 & 700 & 5 \\
\hline 1703 & 500 & 850 & 5 \\
\hline 1ZO4 & 500 & 960 & 30 \\
\hline LZO5 & 100 & 960 & 30 \\
\hline LZO6 & 1400 & 960 & 30 \\
\hline 1207 & 500 & 960 & 30 (vacuum) \\
\hline
\end{tabular}




\section{References}

[1] A. Goyal, D.P. Norton, J.D. Budai, M. Paranthaman Appl. Phys. Lett 69 (12) (1996) 1795-1797; 37

[2] D.P. Norton, A. Goyal, J.D. Budai, D.K. Christen, D.M. Kroeger, E.D. Specht, Q. He, B. Saffian, M. Paranthaman, C. Klabunde, D.F. Lee, B.C.Sales and F.A. List, Science 274 (1996) 755-757.

[3] Y Shiohara, M Yoshizumi, T Izumi and Y Yamada. Supercond. Sci. Technol. 21 (2008) 034002

[4] T. Caroff, S Morlens, A Abrutis, M Decroux, P Chaudouët, L Porcar, Z Saltyte, C Jiménez, P.Odier and F Weiss. Supercond. Sci. Technol. 21 (2008) 075007

[5] K. Knoth, R. Hühne, S. Oswald, L. Molina O. Eibl, L .Schultz, B. Holzapfel

Thin Solid Films 516 (2008) 2099-2108

[6] P. Paranthaman, S. Sathyamurthy, L. Heatherly, P.M. Martin, A.Goyal, T. Kodenkandath, X. Li, C.L.H. Thieme, M.W. Rupich. Physica C 445-448 ( 2006) 529-232.

[7] J.W. Seo, J. Fompeyrine, A. Guiller, G. Norga, C. Marchiori, H. Siegwart, J.P. Locquet. Appl Phys Lett 83, N 25, (2003), 5211-5213.

[8] V. M. Schastlivtsev, V. V. Ustinov, D. P. Rodionov, B. K. Sokolov, I. V. Gervas'eva, Yu. V. Khlebnikova, A. P. Nosov, V. A. Sazonova, V. G. Vasil'ev, E. V. Vladimirova, A. Abaleshev, P. Gierlowski, S. Lewandowski, and H. Szymczak. Doklady Physics Vol 49, No3 (2004) 167-170

[9] L. Rapenne, C. Jiménez, T .Caroff, C. Millon, S. Morlens, P. Bayle-Guillemaud, F.Weiss. In Press in Journal of Materials Research (April)

[10] M. Paranthaman, S.Sathyamurthy, M.S. Bhuiyan, P.M. Martin, T. Aytung, K. Kim, M.Fayek, K.J. Leonard, J. Li, A. Goyal, T. Kodenjandath, X. Li,, W. Zhang, M.W. Rupich . IEEE Trans on Appl. Supercond. Vol 17, 2, (2007) 3332 - 3335.

[11] Z.M. Yu, P. Odier, L. Ortega, L. Zhou, P.X. Zhang, A. Girard Materials Science and Engineering B 130 (2006) 126-131.

[12] M.O. Rikel , D. Isfort, M. Klein, J. Eherenberg, J. Boch, E.D. Specht, M. SunWagner, O. Weber, D. Sporn, S. Engel, O. De Hass, R. Semerad, M. Schubert, B. Holzapfel. Submitted to IEEE Trans. on Appl. Supercond. Presentation 4MX03 in ASC 2008 
[13] S. Engel, R. Hühne, K. Knoth, A. Chopra, N.H. Kumar, V.S. Sarma, P.N. Santhosh, L. Schultz, B. Holzapfel . J. Crystal Growth 310 (2008), 4925-4300.

[14] L. Molina, K. Knoth, S. Engel, B. Holzapfel, O. Eibl. Supercond. Sci. Technol 19 (2006) 1200-1208

[15] M.A. Subramanian, G. Aravamudan, G.V Subba Rao. Prog. Solid. St. Chem. Vol 15 (1983), 55-143.

[16] X.Q. Cao, R. Vassen, WS. Jungen, S. Schwartz, F. Tietz, D. Stöver. J. Am. Ceram. Soc. 84 [9] (2001), 2086-90.

[17] C. J. Brinker, G.W. Scherer. "Chapter 11: Sintering" from "Sol-Gel science. The Physics and Chemistry of Sol-Gel Processing", Academic Press Ltd. London, ISBN 0-12134970-5 (1990).

[18] M.S. Bhuiyan, M. Parnathaman, K. Salama. Supercond. Sci. Technol. 19 (2006) R1R21.
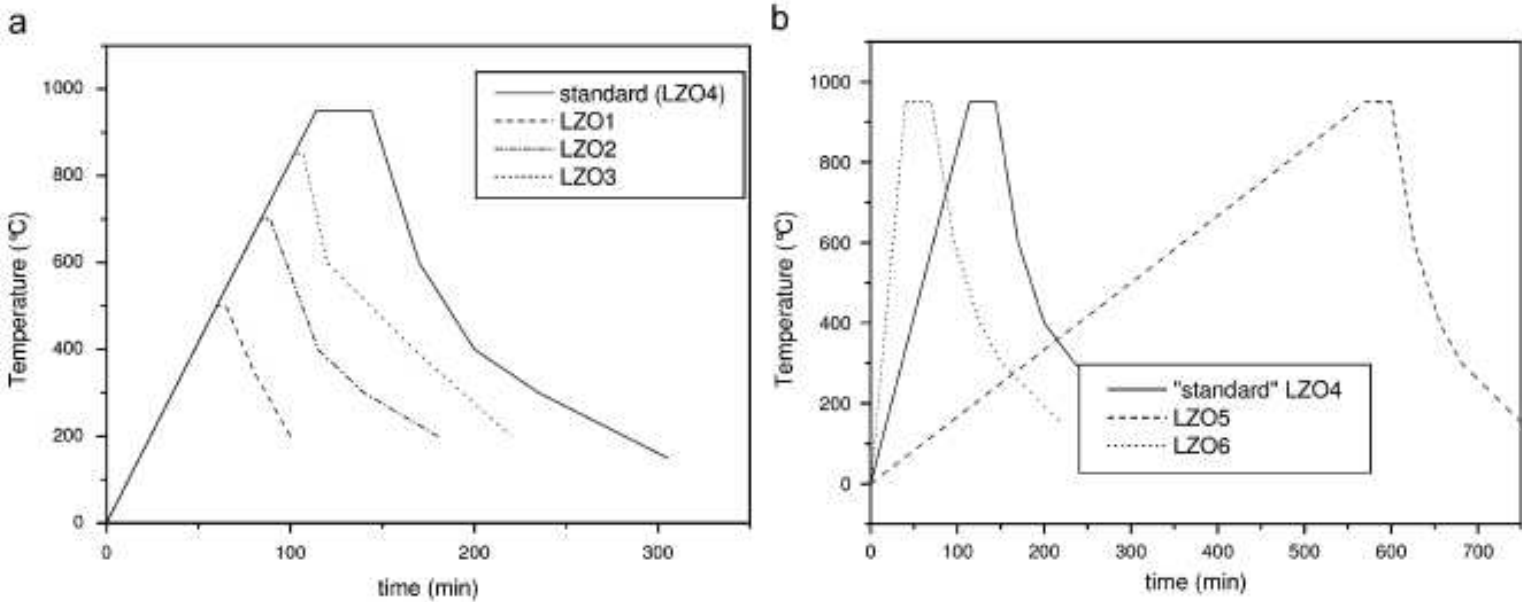

Fig L. Thermal annealing profiles corresponding to samples annealed at (a) different temperatines and (b) diflerent heat ing rates.

a

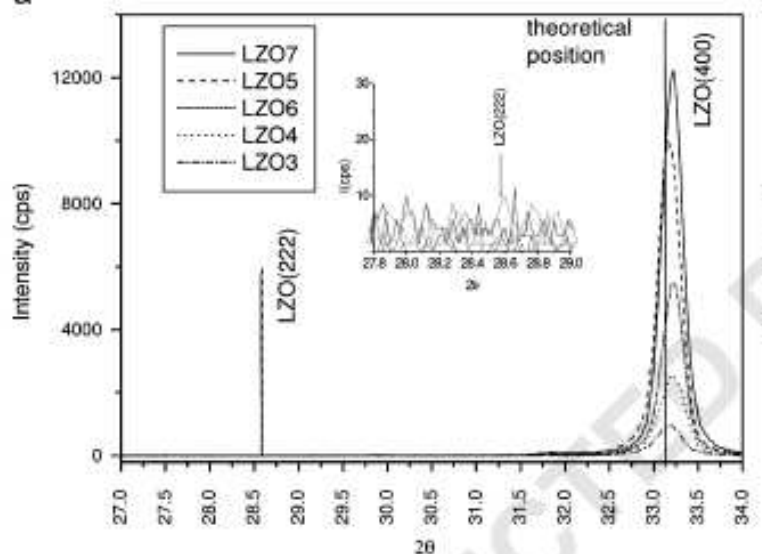

b

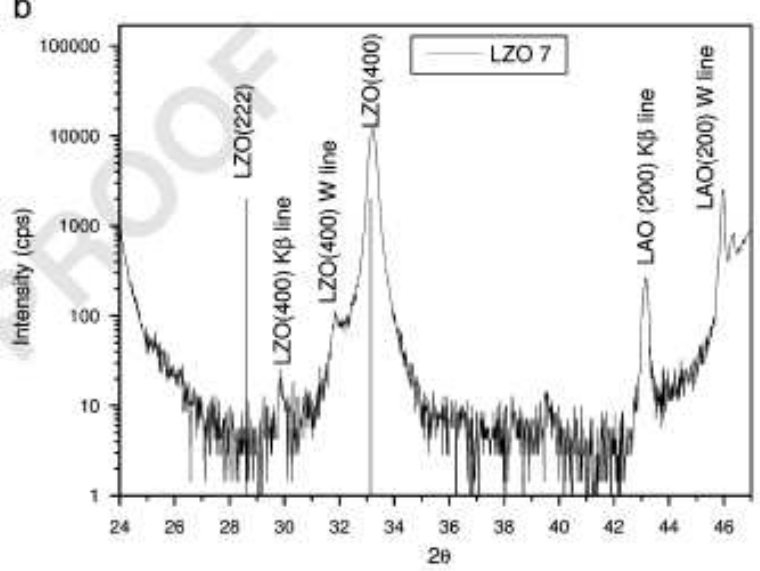

Fig. 2. (a) XRD diagram in $0-2 \theta$ representation for all the studied samples. The 1201 and 1202 samples did not present any diffraction peak. The samples bave been presented taking into accoint the decreasing onder of intensity to simplify the interpretation and (b) logarithmic representation of the XRD diagram from the LZO7 sample. 


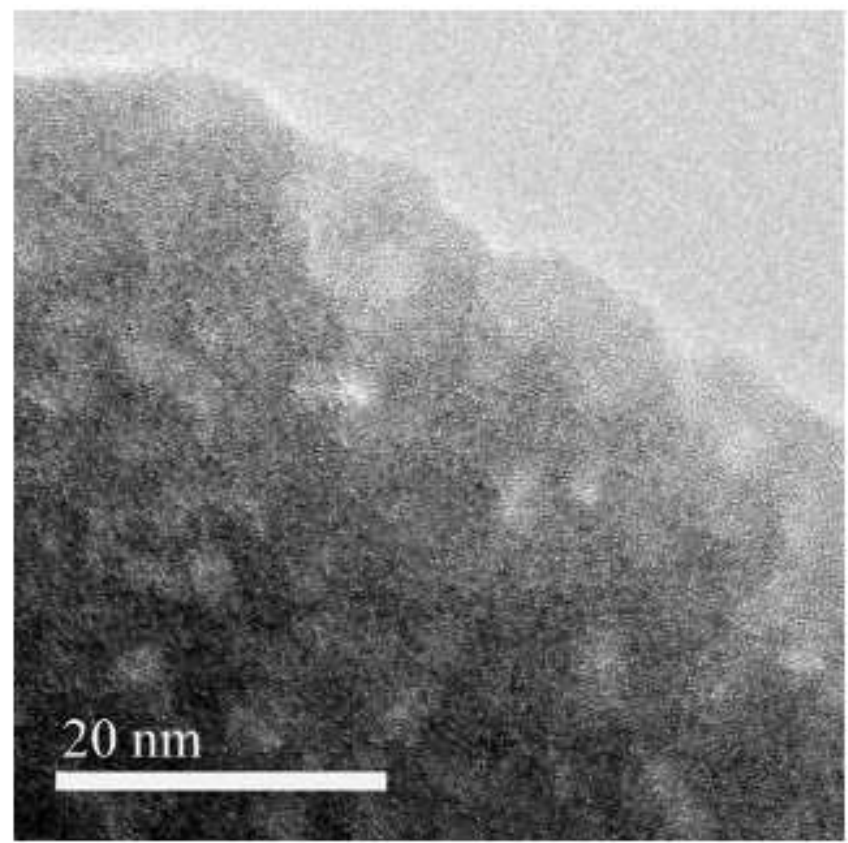

Fig 3. TEM observation in the LAO $|100|$ zone axis of the LZOI sample, annealed at $500{ }^{2} \mathrm{C}$. The sample is amorphous, but the variation of contrast shows the presence of inclusions probabily related to nanocavities formation.

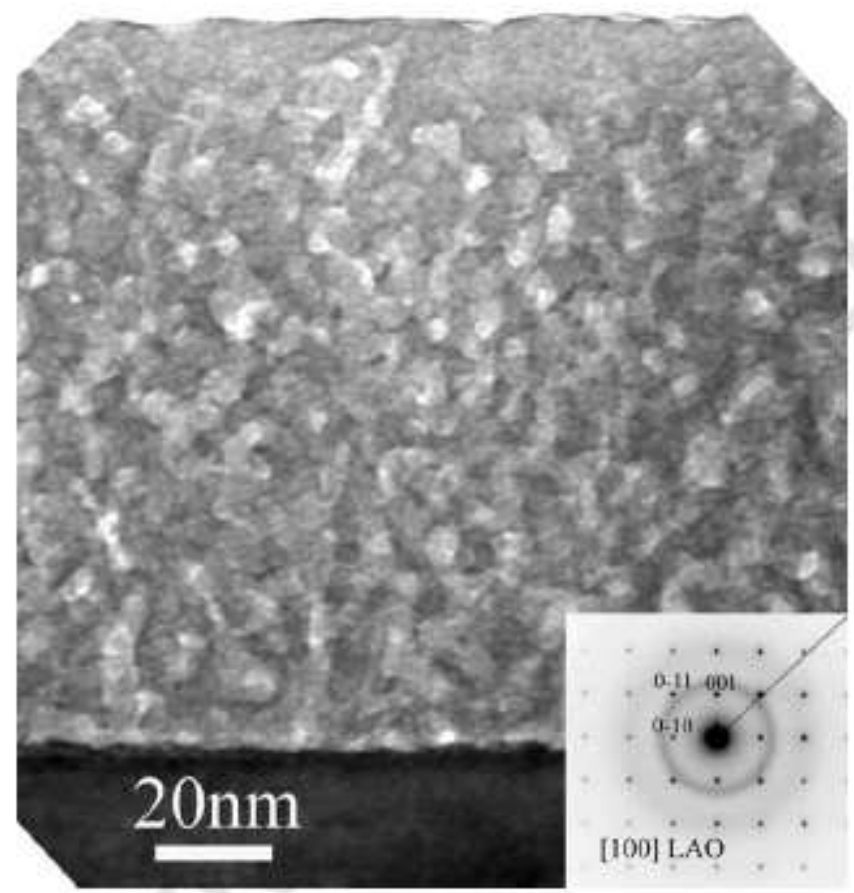

Fig 4. TEM observation in the $L A O[100\}$ zone axis of the $1 Z O 2$ sample, annealed at $700^{\circ} \mathrm{C}$. The sample is still amorphous but the formation of nanocavities is clearty identifiect. 


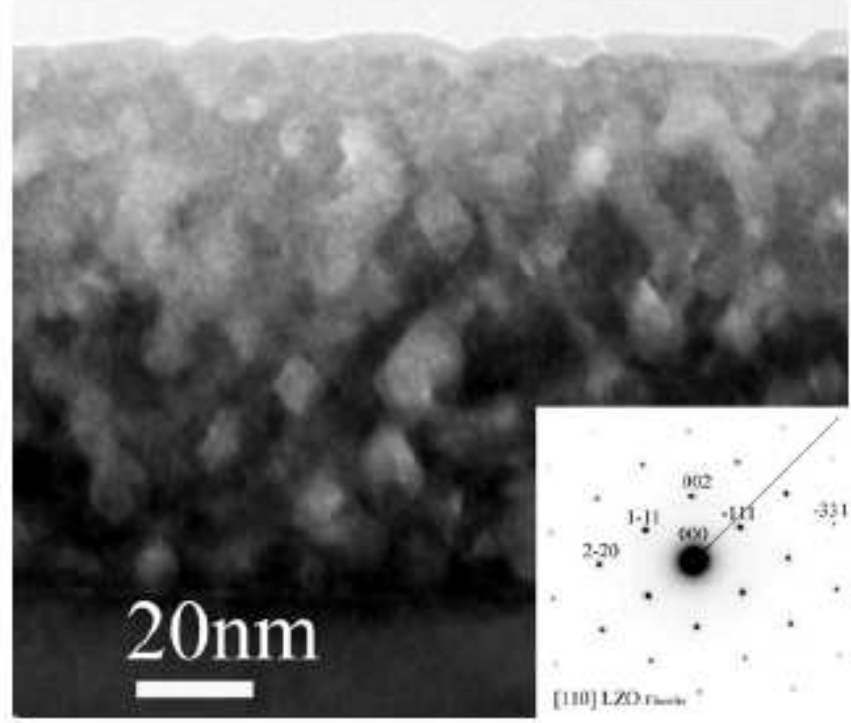

Fig. 5. TEM observation in the $L A O \mid 10$ of zone axis of the 1703 sample, annealed at $850^{\circ} \mathrm{C}$. The sample is completely crystalized in fluorite structure. The electron diffraction pattern corresponds to the 1110$\} 120$ zone axis.

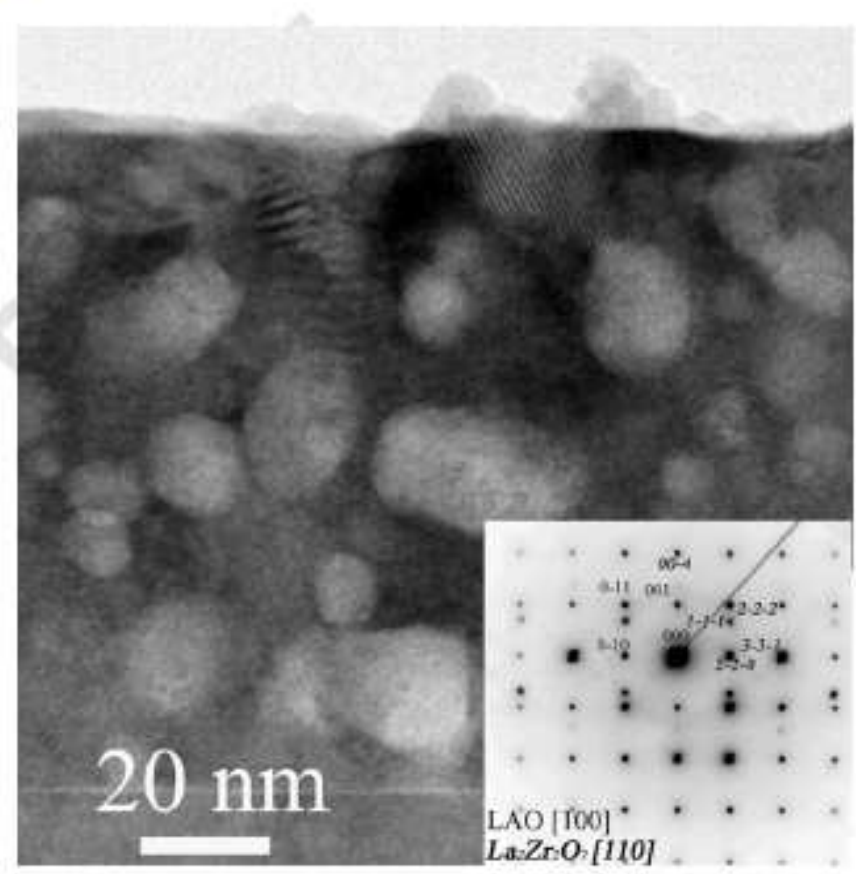

Fig. 6. TEM observation in the LAO $[10$ 0) zone axis of the LTO4 sample, annealed at standard conditions $\left(960^{\circ} \mathrm{C}\right)$. The election diff raction pattem corresponds to the [110] 120 aone axis. The sample is completely crystailized and the pyrochlore structure can be identified by the presence of the (111) and (331) reflections. 


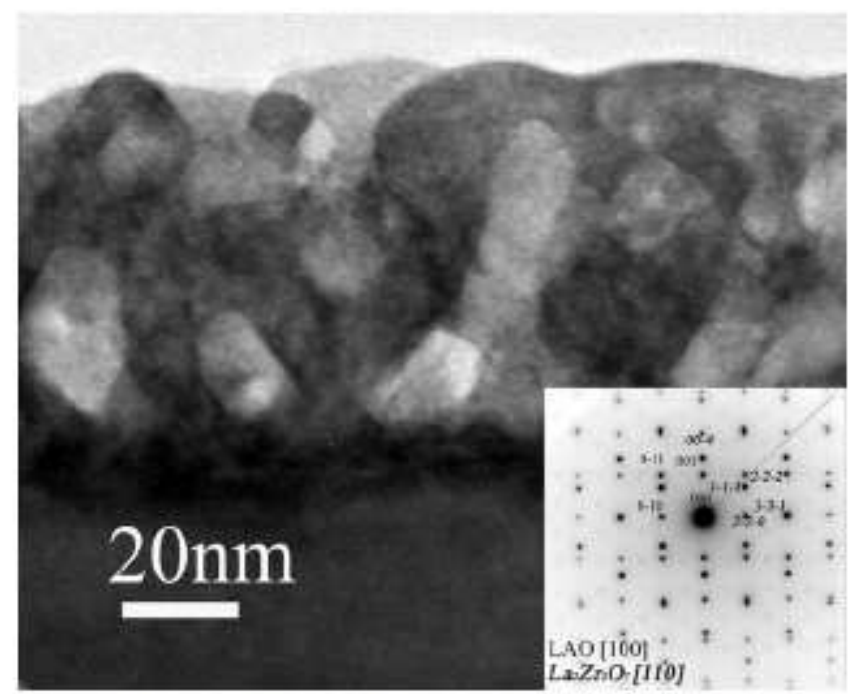

Fig. 7. TEM observation in the $1 A O$ ( 100$)$ zone axis of the $1 Z 05$ sample, annealed with a low hearing rate. The electron diffraction pattern corresponds to the 1110 . IZO zone axis. The sample is completely crystallized in pyrochlore structure. Percolation of voids is visible through the ent ire observed region.

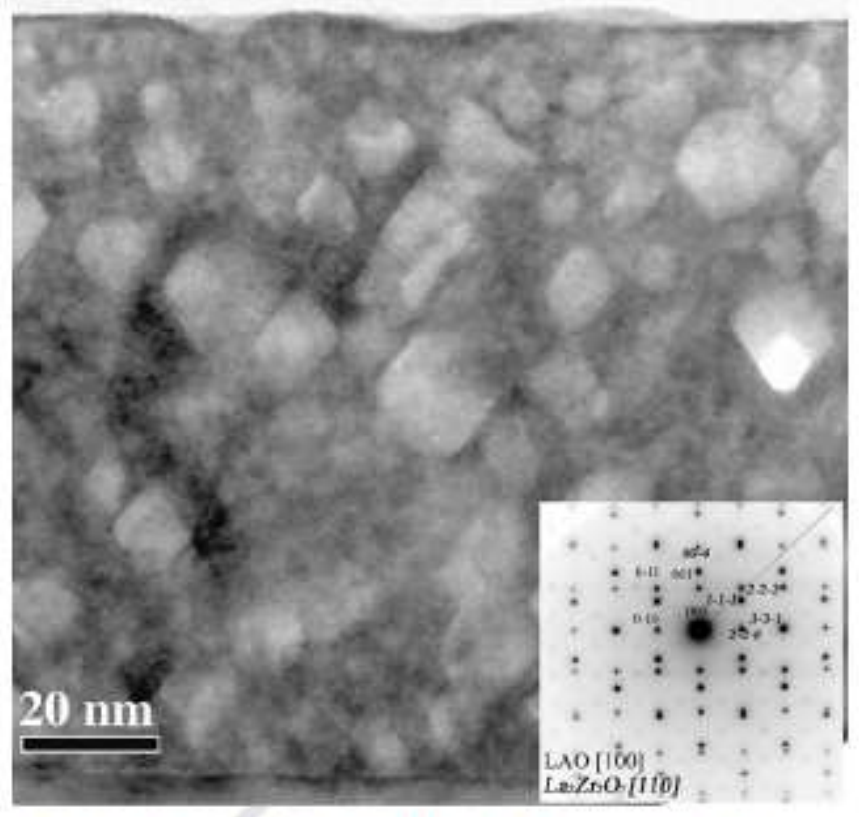

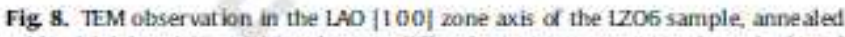
with a high heating rate. The electron diffraction partem corresponids to the $[110\}$ 170 zone axis The sample is completely crystallized in pyrochlore structure. Nanovoids are smaller than for the standard annealing. 


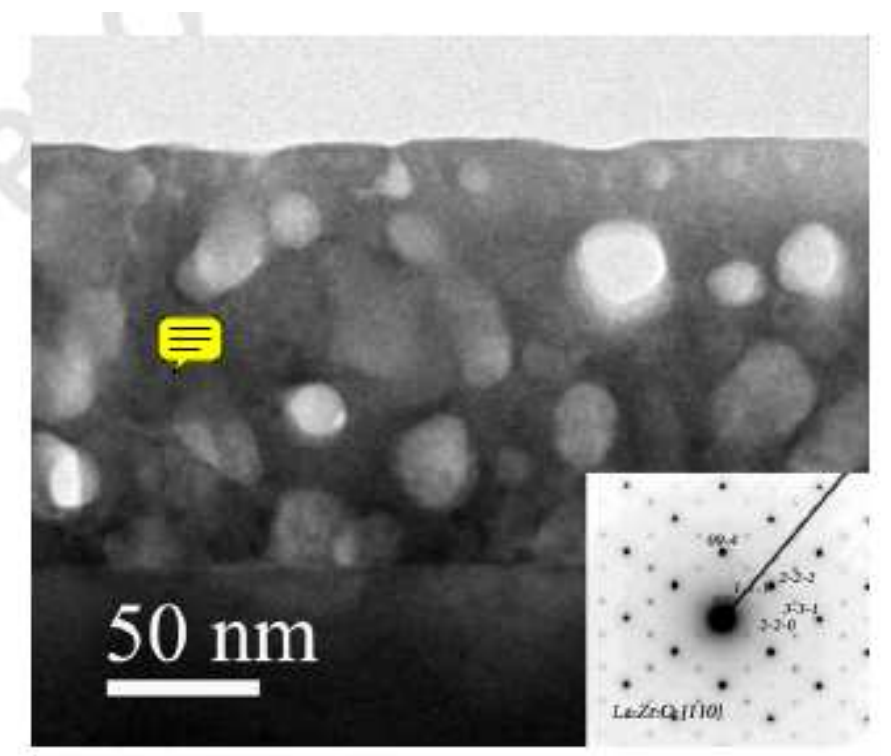

Fig 9. TEM observation in the LAO $\mid 10$ o| 200 axis of the 1207 sample, annealed at standard condicions under vacuum. The electron diffraction pat tern corresponds to the $[11$ 0 120 zone axis. The sample is completely crystallized in pyrochlore structure and presents a very high intensity of the (111) and (331) refections. Nanovoids are spherical and present bigger size than for the standard annealing 